\title{
The dark side of internet: Preliminary evidence for the associations of dark personality traits with specific online activities and problematic internet use
}

\author{
KAGAN KIRCABURUN $^{1 *}$ and MARK D. GRIFFITHS ${ }^{2}$
}

\author{
${ }^{1}$ Faculty of Education, Department of Computer and Instructional Technologies, Duzce University, Duzce, Turkey \\ ${ }^{2}$ International Gaming Research Unit, Psychology Department, Nottingham Trent University, Nottingham, UK
}

(Received: June 25, 2018; revised manuscript received: September 8, 2018; second revised manuscript received: September 28, 2018; accepted: September 28, 2018)

\begin{abstract}
Background and aims: Research has shown that personality traits play an important role in problematic internet use (PIU). However, the relationship between dark personality traits (i.e., Machiavellianism, psychopathy, narcissism, sadism, and spitefulness) and PIU has yet to be investigated. Consequently, the objectives of this study were to investigate the relationships of dark traits with specific online activities (i.e., social media, gaming, gambling, shopping, and sex) and PIU. Methods: A total of 772 university students completed a self-report survey, including the Dark Triad Dirty Dozen Scale, Short Sadistic Impulse Scale, Spitefulness Scale, and an adapted version of the Bergen Facebook Addiction Scale. Results: Hierarchical regression analysis and a multiple mediation model indicated that being male was positively associated with higher online gaming, online sex, and online gambling, and negatively associated with social media and online shopping. Narcissism was related to higher social media use; Machiavellianism was related to higher online gaming, online sex, and online gambling; sadism was related to online sex; and spitefulness was associated with online sex, online gambling, and online shopping. Finally, Machiavellianism and spitefulness were directly and indirectly associated with PIU via online gambling, online gaming, and online shopping, and narcissism was indirectly associated with PIU through social media use. Discussion: Findings of this preliminary study show that individuals high in dark personality traits may be more vulnerable in developing problematic online use and that further research is warranted to examine the associations of dark personality traits with specific types of problematic online activities.
\end{abstract}

Keywords: problematic internet use, psychopathy, Machiavellianism, spitefulness, sadism, narcissism

\section{INTRODUCTION}

The latest beta draft version of the 11th revision of the International Classification of Diseases (World Health Organization, 2017) has recognized "gaming disorder, predominantly online," as an official diagnosis, and the latest edition of the Diagnostic and Statistical Manual of Mental Disorders (American Psychiatric Association, 2013) has included Internet Gaming Disorder in Section 3 as an emerging mental health issue that should be further investigated. Despite differing opinions as whether to consider problematic online activities, other than Internet Gaming Disorder, as behavioral addictions (Mann, Kiefer, Schellekens, \& Dom, 2017), empirical evidence suggests that a small minority of individuals report problematic online behaviors, such as problematic internet use (PIU; Kuss, Griffiths, Karila, \& Billieux, 2014). There are several terms that have been widely used to describe problematic internet engagement including "internet addiction," "internet use disorder," "excessive internet use," "internet dependency," and "compulsive internet use," although these terms describing problematic online use often use similar diagnostic criteria (Kuss et al., 2014). One of the most widely used symptomatology frameworks is grounded within the biopsychosocial framework of addiction and consists of six core components that comprise problematic engagement in any behavior (i.e., salience, preoccupation, mood modification, tolerance, withdrawal, and conflict; Griffiths, 2005). Elsewhere, PIU has been referred to as the preoccupation with and loss of control over internet use that leads to impairments in an individual's social life, health, fulfillment of their real-life duties (e.g., occupation and/or education), and sleep and eating patterns (Spada, 2014). For the sake of consistency, this study uses the term "problematic internet use" to describe a range of similar and/or overlapping online addictive, compulsive, and/or excessive behaviors. PIU is arguably a more global (and "catch-all" term) than internet use disorder, given that PIU does not necessarily mean that individuals are suffering from a disorder.

Prevalence rates of PIU vary greatly (between $1 \%$ and $18 \%$ ) across different studies (for a review, see Kuss et al., 2014). PIU is an important health issue especially among

\footnotetext{
* Corresponding author: Kagan Kircaburun; Faculty of Education, Department of Computer and Instructional Technologies, Duzce University, Konuralp Campus, Duzce 81620, Turkey; Phone: +90 0380542 1355; Fax: +90 0380542 1366; E-mail: kircaburunkagan@ gmail.com
}

This is an open-access article distributed under the terms of the Creative Commons Attribution-NonCommercial 4.0 International License, which permits unrestricted use, distribution, and reproduction in any medium for non-commercial purposes, provided the original author and source are credited, a link to the CC License is provided, and changes - if any - are indicated. 
adolescents and emerging adults because of their higher rates of everyday internet access (Anderson, Steen, \& Stavropoulos, 2017). Negative consequences of PIU among a minority of individuals have included depression, anxiety, stress, loneliness (Ostovar et al., 2016), daytime sleepiness, lack of energy, and physiological dysfunction (Kuss et al., 2014). These impairments have led researchers to investigate PIU risk factors in order to develop prevention strategies for PIU.

According to the Interaction of Person-Affect-CognitionExecution model (I-PACE), which is one of the theoretical frameworks proposed to explain underlying mechanisms of PIU (Brand, Young, Laier, Wölfling, \& Potenza, 2016), personality, social cognitions, biopsychological constitution, and specific online use motives are among the core factors that are associated with the development and maintenance of PIU. These factors can be interrelated and may potentially play mediating roles with each other concerning their relationships involving PIU (Brand et al., 2016). Therefore, when considering PIU, it is of importance that the interaction of personality differences with specific online use motives (e.g., gaming, gambling, sex, social media, and shopping) should be considered.

Regarding the personality determinants of PIU, a metaanalytic review noted the consistent role of the Big Five personality traits in the development of PIU. More specifically, PIU was associated with higher neuroticism, lower extraversion, lower conscientiousness, lower openness to experience, and lower agreeableness (Kayiş et al., 2016). A cross-sectional study reported a significant relationship between PIU and HEXACO personality dimensions of conscientiousness, honesty-humility, and emotionality (Kopuničová \& Baumgartner, 2016). Other studies have found higher PIU to be associated with novelty-seeking, fun-seeking, low self-concept, and negative emotion avoidance (Kuss et al., 2014). However, despite a large body of empirical literature regarding the impact of personality on PIU, the role of dark personality traits has been neglected.

The present study focused on Machiavellianism, psychopathy, narcissism, sadism, and spitefulness with PIU because of the common correlates of these personality constructs (e.g., callousness, low agreeableness, lower conscientiousness, aggressiveness, higher dissociation, higher borderline personality features, and greater sensational interests) associated with elevated levels of PIU (Dalbudak, Evren, Aldemir, \& Evren, 2014; Douglas, Bore, \& Munro, 2012; James, Kavanagh, Jonason, Chonody, \& Scrutton, 2014; Kayiş et al., 2016; Lu et al., 2017; Richardson \& Boag, 2016; Trumello, Babore, Candelori, Morelli, \& Bianchi, 2018). Dark personality traits have been associated with antisocial online behaviors including odd status updates, cyberbullying, and online trolling, as well as fulfilling various psychological needs using different platforms (Craker \& March, 2016; Garcia \& Sikström, 2014; Panek, Nardis, \& Konrath, 2013). Moreover, a recent study found and argued that Machiavellianism and narcissism were positively associated with problematic social media use, which may be about fulfilling antisocial needs of individuals high on these traits (Kircaburun, Demetrovics, \& Tosuntaş, 2018). Many activities can now be facilitated by internet (e.g., social media use, online gaming, online gambling, cybersex, and online shopping) that may appeal to varied needs of individuals with different personality characteristics. Consequently, dark personality traits may be associated with different online activities and PIU. Therefore, this study investigated the relationships between dark personality traits, specific online activities, and PIU.

\section{Dark personality traits and PIU}

The Dark Triad is the constellation of three overlapping undesirable and antisocial personality constructs: Machiavellianism, psychopathy, and narcissism (Paulhus \& Williams, 2002). These traits have drawn increasing attention among researchers over the past decade. More recently, it has been suggested that the Dark Triad should be expanded to the Dark Tetrad with the addition of sadism (Buckels, Trapnell, \& Paulhus, 2014; van Geel, Goemans, Toprak, \& Vedder, 2017). In addition, some studies have examined the role of spitefulness alongside the Dark Tetrad traits (Jonason, Zeigler-Hill, \& Okan, 2017; Zeigler-Hill \& Vonk, 2015). However, some scholars have argued that the contribution of sadism and spitefulness to the Dark Triad is unclear and further empirical evidence is needed (Jonason et al., 2017; Tran et al., 2018). Despite the common core elements of the dark personality traits such as interpersonal manipulation and callousness (Jones \& Figueredo, 2013; Marcus, Preszler, \& Zeigler-Hill, 2018), these traits have distinct features that may generate vulnerability for problematic online use.

Narcissism, which refers to a grandiose sense of selfimportance, superiority, dominance, and entitlement (Corry, Merritt, Mrug, \& Pamp, 2008), has been associated with a higher involvement in problematic social media use (Andreassen, Pallesen, \& Griffiths, 2017; Kircaburun, Demetrovics, et al., 2018), problematic online game use (Kim, Namkoong, Ku, \& Kim, 2008), and PIU (Pantic et al., 2017). Those high in narcissism report higher engagement in self-promoting (sometimes deceptive) online behaviors, such as selfie-editing and posting especially among men (Arpaci, 2018; Fox \& Rooney, 2015), whereas selfpromotion and presenting a more popular self on social media are important risk factors for problematic online use (Kircaburun, Alhabash, Tosuntaş, \& Griffiths, 2018). Narcissistic individuals may experience higher belongingness and admiration using online social media (Casale \& Fioravanti, 2018), and/or engage in online gaming as a way to feel superior to their competitors (Kim et al., 2008). Futhermore, both social media use and online gaming use can lead to PIU in a minority of individuals (Király et al., 2014).

Machiavellianism, which refers to being deceptive, manipulative, ambitious, and exploitative (Christie \& Geis, 1970), has been associated with problematic social media use (Kircaburun, Demetrovics, et al., 2018), trolling in online games (Ladanyi \& Doyle-Portillo, 2017), online self-monitoring, and self-promotion (Abell \& Brewer, 2014). Machiavellians may choose social media and gaming platforms to engage in interpersonal manipulation or deceptive self-promotion (Abell \& Brewer, 2014; Ladanyi \& Doyle-Portillo, 2017) partly because of their fear of social rejection (Rauthmann, 2011). Given the potentially 
obsessive nature of these behaviors, these problematic online behaviors may be associated with addiction-like symptoms such as preoccupation and mood modification (Griffiths, 2005), and in turn, develop into PIU for a small minority of individuals (Kircaburun, Demetrovics, et al., 2018). Moreover, Machiavellianism is negatively related to positive mood (Egan, Chan, \& Shorter, 2014) and positively to elevated levels of stress (Richardson \& Boag, 2016). Given that problematic online use is a maladaptive coping strategy against negative feelings (Kuss et al., 2014), it is logical to expect some individuals high in Machiavellianism to engage in PIU and become problematic users.

Psychopathy has been characterized by high impulsivity, recklessness, and low empathy (Jonason, Lyons, Bethell, \& Ross, 2013). Similar to Machiavellianism, psychopathy has also been associated with emotion dysregulation and lower positive mood (Egan et al., 2014; Zeigler-Hill \& Vonk, 2015). In addition to psychopaths' potential proneness to PIU as a maladaptive coping strategy (Kuss et al., 2014), they may engage in PIU in an attempt to seek and obtain higher sensation (Lin \& Tsai, 2002; Vitacco \& Rogers, 2001). Similarly, individuals high on sadistic impulses engage in deviant and antisocial online behaviors, such as cyberbullying (van Geel et al., 2017), online trolling (Buckels et al., 2014), intimate partner cyberstalking (Smoker \& March, 2017), as well as violent video game playing (Greitemeyer \& Sagioglou, 2017). Moreover, psychopaths and sadists may try to gratify sexual urges online (e.g., cybersex and pornography viewing) and live out their fantasies (Baughman, Jonason, Veselka, \& Vernon, 2014) in order to increase sexual arousal and stimulation (Shim, Lee, \& Paul, 2007). Sadists may try to compensate their need for cruelty (O'Meara, Davies, \& Hammond, 2011) that they cannot fulfill in real world in online contexts. Successful attempts may lead to problematic use via positive mood modification.

Spitefulness, which has been referred as being willing to suffer harm to oneself in order to harm others (Zeigler-Hill, Noser, Roof, Vonk, \& Marcus, 2015), is a distinct personality dimension that is understudied but overlaps with different personality constructs, such as aggression, Machiavellianism, psychopathy, low self-esteem, low empathy, and low emotional intelligence (Marcus, Zeigler-Hill, Mercer, \& Norris, 2014; Zeigler-Hill et al., 2015). These constructs are important risk factors for antisocial and problematic online behaviors (Kuss et al., 2014). Consequently, higher spitefulness may be a potential risk factor for problematic online use. Given the increased likelihood of individuals high in spitefulness to experience problematic real-life social interactions because of their antisocial personality facets, such as interpersonal manipulation (Marcus et al., 2014) and injurious humor styles (Vrabel, Zeigler-Hill, \& Shango, 2017), they may be more prone to engage in higher problematic online use in order to avoid real-life social relationships and/or to manipulate others more easily (Kircaburun, Demetrovics, et al., 2018; Kircaburun, Kokkinos, et al., 2018). Furthermore, increased levels of impulsivity of spiteful individuals (Jonason et al., 2013; Marcus et al., 2014) can put individuals in a vulnerable position for experiencing PIU, because impulsivity is one of the consistent predictors of PIU (Kuss et al., 2014).

\section{The role of specific online activities}

The internet is a medium that facilitates use of different behaviors and activities, such as using social media, gaming, gambling, shopping, and sex (Griffiths, 2000; Montag et al., 2015). Most of these activities already exist in offline contexts apart from social media use. Therefore, it is possible that individuals' offline behaviors can migrate into online ones in an attempt to compensate unmet offline needs (Kardefelt-Winther, 2014), such as gaming, gambling, sex, shopping, and communication. According to the I-PACE model (Brand et al., 2016), an individual's personality is an important determinant for the preference of use of specific online platforms and/or applications. The aforementioned empirical evidence on how individuals with different personality facets can obtain diversified gratifications from different online activities provides validation of the I-PACE model.

As previously noted, engaging in online activities can become addictive and lead to PIU for a small minority of individuals. For instance, online gaming has been associated with problematic gaming. However, in addition to online gaming, online social media use has also been found to predict higher PIU, while problematic gaming was only associated with online gaming (Király et al., 2014). Consequently, PIU may be referred to as the general overuse of the internet across its different activities. Therefore, it may be that engaging in these aforementioned online activities relate to higher PIU and account for the relationships between dark personality traits and PIU. Some empirical evidence appears to support this assumption via reporting significant relationships of online gaming, gambling, and pornography viewing with PIU (Alexandraki, Stavropoulos, Burleigh, King, \& Griffiths, 2018; Critselis et al., 2013; Stavropoulos, Kuss, Griffiths, Wilson, \& Motti-Stefanidi, 2017). Consequently, it may be that different dark personality traits direct individuals to use different online activities, and in turn, obtaining gratifications from their preferred online activities may lead to repeated and problematic use of internet. Thus, it is expected that the dark personality traits will relate to PIU using indirect pathways through specific online activities.

\section{The present study}

This is the first study to investigate the direct and indirect associations of dark personality traits (i.e., Machiavellianism, psychopathy, narcissism, sadism, and spitefulness) with PIU through specific online activities (i.e., social media, online gaming, online gambling, online shopping, and online sex). Previous studies have mostly focused on the relationships of three dark personality traits (i.e., Machiavellianism, psychopathy, and narcissism) across different online behaviors. However, no study has ever considered five different traits (i.e., the Dark Triad in addition to sadism and spitefulness) with uses of different online activities and PIU simultaneously. It was expected that there would be a mediating effect from online activities between personality constructs and PIU. Based on the theoretical assumptions of I-PACE model (which asserts that interrelated core factors such as personality traits and specific online use motives can 
play a mediating role on their relationship to PIU) and existing empirical evidence, this study formulated and tested several hypotheses while controlling for gender and age.

H1: Narcissism and Machiavellianism will be directly associated with PIU and indirectly via social media and online gaming (Kim et al., 2008; Kircaburun, Demetrovics, et al., 2018; Ladanyi \& Doyle-Portillo, 2017).

H2: Psychopathy and sadism will be directly associated with PIU and indirectly via online sex (Buckels et al., 2014; Lin \& Tsai, 2002; Vitacco \& Rogers, 2001).

H3: Psychopathy and spitefulness will be directly associated with PIU and indirectly via online gambling (Jonason et al., 2013; Marcus et al., 2014).

\section{METHODS}

\section{Participants and procedure}

A total of 772 Turkish university students ( $64 \%$ female), aged between 18 and 28 years (mean $=20.72$ years, $S D=2.30$ ), completed paper-and-pencil questionnaires. All of the participants were informed about the details of the study and gave their informed consent. Participation in the study was anonymous and voluntary. Data used in this study were collected simultaneously with another study published elsewhere (i.e., Kircaburun, Jonason, \& Griffiths, 2018a).

\section{Measures}

Personal information form. In order to obtain information regarding participants' gender, age, and specific online activities engaged in, a personal information form was used. Participants used a 5-point Likert scale from "never" to "always" in order to indicate their online use of gambling (i.e., "I use the internet for gambling"), gaming (i.e., "I use the internet for gaming"), shopping (i.e., "I use the internet for shopping"), social media (i.e., "I use the internet for social media"), and sex (i.e., "I use the internet for sex").

Dark Triad Dirty Dozen (Jonason \& Webster, 2010). The scale comprises 12 items on a 9-point Likert scale from "strongly disagree" to "strongly agree," with four items for each personality dimension including Machiavellianism (e.g., "I have used deceit or lied to get my way"), psychopathy (e.g., "I tend to not be too concerned with morality or the morality of my actions"), and narcissism (e.g., "I tend to want others to pay attention to me"). The Turkish form of the scale previously reported high validity and reliability (Özsoy, Rauthmann, Jonason, \& Ardıç, 2017). The scale had adequate-to-good internal consistency in this study (Cronbach's $\alpha=.67-.88$ ).

Short Sadistic Impulse Scale (O'Meara et al., 2011). The scale comprises 10 dichotomous ("unlike me" and "like me") items (e.g., "I have fantasies which involve hurting people"). The Turkish form of the scale previously reported high validity and reliability (Kircaburun, Jonason, \& Griffiths, 2018b). The scale had good internal consistency in this study $(\alpha=.77)$.

Spitefulness Scale (Marcus et al., 2014). The original scale comprises 17 items (e.g., "It might be worth risking my reputation in order to spread gossip about someone I did not like") on a 5-point Likert scale from "never" to "always." In this study, 11 items compatible with Turkish university students were chosen for exploratory (EFA) and confirmatory factor analyses (CFA). As a result, EFA $(\mathrm{KMO}=0.90 ; p<.001$; communalities ranging between 0.29 and 0.59 ; explaining $48 \%$ of the variance) and CFA (standardized regression weights ranging between 0.49 and 0.72 ) produced two subfactors, conceptualized as harming others (e.g., "If I had the opportunity, then I would gladly pay a small sum of money to see a classmate who I do not like fail his or her final exam") and troubling others (e.g., "If I was one of the last students in a classroom taking an exam and I noticed that the instructor looked impatient, I would be sure to take my time finishing the exam just to irritate him or her"). Second-order CFA $\left(\chi^{2} / d f=2.67\right.$, RMSEA $=0.05$ $[90 \% \mathrm{CI}(0.04,0.06)], \mathrm{CFI}=0.97, \mathrm{GFI}=0.97)$ showed that the scale can be used in a unidimensional way. The scale had good internal consistency in this study $(\alpha=.84)$.

Bergen Internet Addiction Scale (BIAS; Tosuntaş, Karadağ, Kircaburun, \& Griffiths, 2018). The Turkish BIAS was used to assess internet addiction. The BIAS was developed by adapting the Bergen Facebook Addiction Scale (Andreassen, Torsheim, Brunborg, \& Pallesen, 2012). The Turkish BIAS (Tosuntaş et al., 2018) simply replaced the word "Facebook" with the word "internet." The BIAS comprises six items (e.g., "How often during the last year have you tried to cut down on the use of internet without success?") on a 5-point Likert scale from "never" to "always." The Turkish form of the scale previously reported high validity and reliability. The scale had good internal consistency in this study $(\alpha=.83)$.

\section{Ethics}

Ethical approval for the study was received from the faculty administrative boards before the recruitment of the participants, and complied with the Declaration of Helsinki.

\section{RESULTS}

Descriptive statistics, skewness, kurtosis, and variance inflation factor (VIF) values, and correlations between gender, age, Dark Tetrad traits, spitefulness, specific online activities, and PIU are shown in Table 1. Before carrying out hierarchical multiple regression analysis, skewness, kurtosis, VIF, and tolerance values were examined to make sure that abnormal distribution and multicollinearity were not detected. According to West, Finch, and Curran (1995), skewness and kurtosis thresholds for normality are \pm 2 and \pm 7 , respectively, whereas Kline (2011) has a more liberal approach with \pm 3 and \pm 8 , respectively, although some conservative guidelines assume violation of normal distribution if skewness and kurtosis values were \pm 2 (George \& Mallery, 2010). In this study, variables were not transformed nor were non-parametric tests used because, when skewness value is below the threshold, normality assumption violations caused by kurtosis can be neglected in larger samples (Tabachnick \& Fidell, 2001). Hierarchical regression analysis (Table 2) was applied to examine the personality predictors of specific online activities while controlling 
Dark traits and problematic internet use
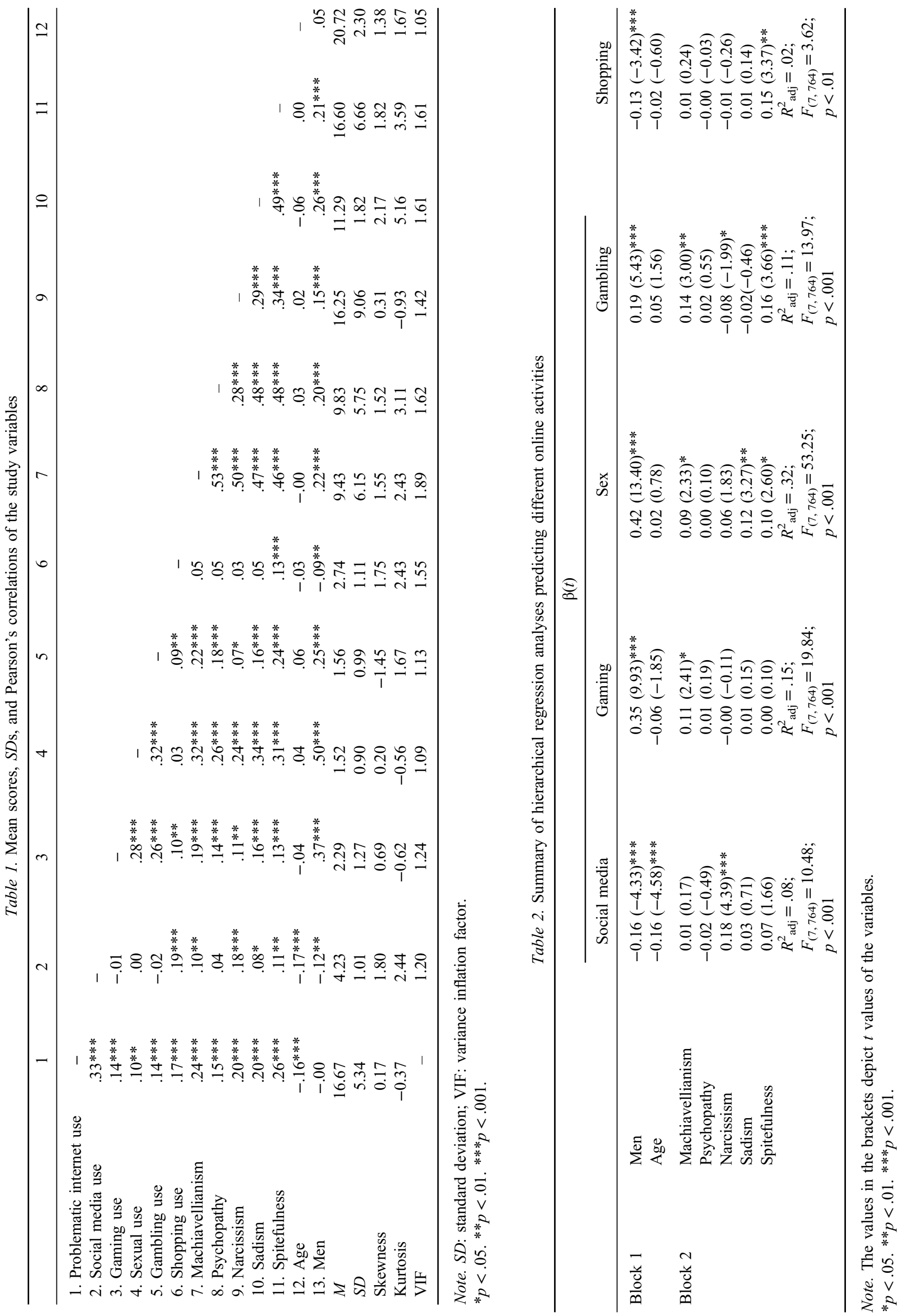


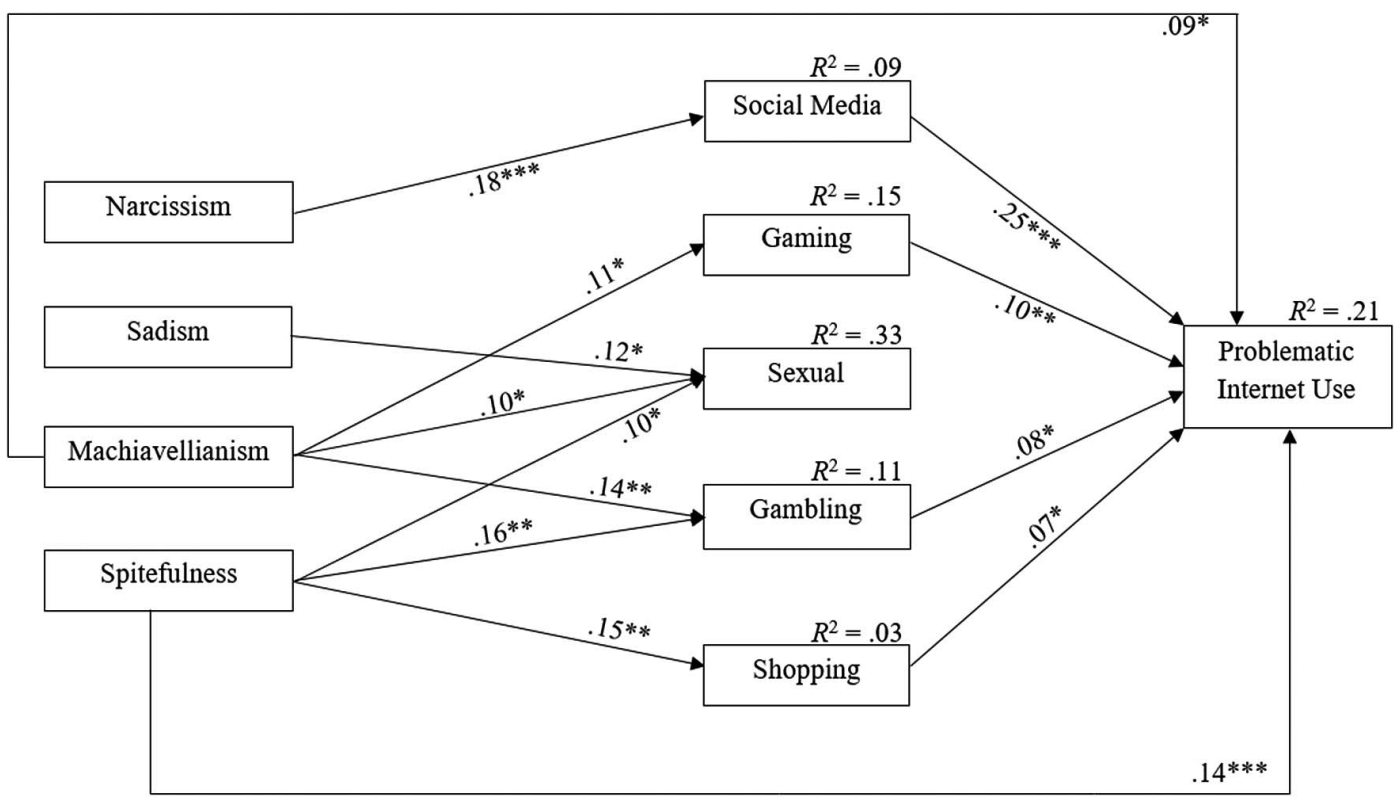

Figure 1. Final model of the significant path coefficients. Gender and age were adjusted for mediator and outcome variables in the model. For clarity, control variables and correlations between independent, control, and mediator variables have not been depicted in the figure. ${ }^{*} p<.05$.

$$
{ }^{* *} p<.01 .{ }^{* * *} p<.001
$$

Table 3. Standardized estimates of total, direct, and indirect effects on problematic internet use and mediator variables

\begin{tabular}{llc}
\hline & Effect $(S E)$ & Total effect explained (\%) \\
\hline Machiavellianism $\rightarrow$ Problematic internet use (total effect) & - \\
Machiavellianism $\rightarrow$ Problematic internet use (direct effect) & $0.12(0.05)^{*}$ & 75 \\
Machiavellianism $\rightarrow$ Problematic internet use (total indirect effect) & $0.09(0.05)^{*}$ & 25 \\
Machiavellianism $\rightarrow$ Gambling $\rightarrow$ Problematic internet use (indirect effect) & $0.03(0.02)$ & $0.01(0.01)^{*}$ \\
Machiavellianism $\rightarrow$ Gaming $\rightarrow$ Problematic internet use (indirect effect) & $0.01(0.01)^{*}$ & 8 \\
Narcissism $\rightarrow$ Problematic internet use (total effect) & $0.09(0.04)^{*}$ & 8 \\
Narcissism $\rightarrow$ Problematic internet use (direct effect) & $0.05(0.04)$ & - \\
Narcissism $\rightarrow$ Social media use $\rightarrow$ Problematic internet use (indirect effect) & $0.04(0.02)^{*}$ & 56 \\
Spitefulness $\rightarrow$ Problematic internet use (total effect) & $0.18(0.04)^{* * *}$ & 44 \\
Spitefulness $\rightarrow$ Problematic internet use (direct effect) & $0.14(0.04)^{* * *}$ & - \\
Spitefulness $\rightarrow$ Problematic internet use (total indirect effect) & 78 \\
Spitefulness $\rightarrow$ Gambling $\rightarrow$ Problematic internet use (indirect effect) & $0.04(0.02)^{* *}$ & 22 \\
Spitefulness $\rightarrow$ Shopping $\rightarrow$ Problematic internet use (indirect effect) & $0.02(0.01)^{*}$ & 11 \\
\hline
\end{tabular}

Note. ${ }^{*} p<.05 .{ }^{* *} p<.01 .{ }^{* * *} p<.001$.

for gender and age using SPSS 23 software. Being male was positively associated with online gaming $(\beta=0.35$, $p<.001)$, online sex $(\beta=0.42, p<.001)$, and online gambling $(\beta=0.19, p<.001)$, and negatively with social media use $(\beta=-0.16, p<.001)$ and online shopping $(\beta=-0.13$, $p<.001)$. Age was associated only with social media use $(\beta=-0.16, p<.001)$. Narcissism was related to social media use $(\beta=0.18, p<.001)$; Machiavellianism was associated with online gaming $(\beta=0.11, p<.05)$ and online sex $(\beta=0.09, p<.05)$. Those high in spitefulness scored higher on online sex $(\beta=0.10, p<.05)$, online gambling $(\beta=0.16, \quad p<.001)$, and online shopping $(\beta=0.15$, $p<.01)$. Finally, sadism was only associated with online $\operatorname{sex}(\beta=0.12, p<.01)$.

In order to examine possible mediation effects of online activities between personality traits and PIU, a saturated multiple mediation model was tested with dark personality traits as independent variables, specific online activities as mediators, PIU as the outcome variable, and gender and age as control variables (Figure 1). AMOS 23 software was run for the path analysis using bootstrapping method with 5,000 bootstrapped samples and 95\% bias-corrected confidence intervals. Indirect pathways were examined using an estimand (Gaskin, 2016). As a result of analyses (Table 3), Machiavellianism was directly and indirectly associated with PIU through online gambling and online gaming $(\beta=0.12$, $p<.05 ; 95 \%$ CI $[0.02,0.21])$. Narcissism was indirectly associated with PIU through social media use $(\beta=0.09$, $p<.05 ; 95 \%$ CI $[0.00,0.18])$. Finally, spitefulness was directly and indirectly associated with PIU through online gambling and online shopping $(\beta=0.18, p<.001 ; 95 \%$ CI $[0.10,0.26])$. The model explained $21 \%$ of the variance in PIU.

\section{DISCUSSION}

To the best of authors' knowledge, this is the first study to investigate the direct and indirect associations of dark 
personality traits (i.e., Machiavellianism, psychopathy, narcissism, sadism, and spitefulness) with PIU through specific online activities (i.e., social media, online gaming, online gambling, online shopping, and online sex). According to analyses, and consistent with I-PACE model, different personality traits were associated with different online activities and levels of PIU. However, it should be noted that most of the effect sizes between variables were small. While the relationship between narcissism and PIU was fully mediated by social media use, Machiavellianism was directly and indirectly associated with PIU via online gambling and online gaming. Finally, online gambling and online shopping partially mediated the association between spitefulness and PIU. While first and third hypotheses were partially supported, findings were not in line with the second hypothesis.

Partially consistent with the hypothesis, social media use mediated the relationship between narcissism and PIU. Narcissism was related to higher social media use, and in turn, higher social media use was associated with higher PIU. It appears that individuals high in narcissism preferred social media to online gaming platforms in order to fulfill their psychological needs arising from their antisocial personality such as need for admiration (Casale \& Fioravanti, 2018). Narcissists use different social media tools to promote and monitor themselves, which may turn into preoccupation with their profiles and others' comments on their posts (Kircaburun, Demetrovics, et al., 2018). In turn, this preoccupation may transform into PIU for a small number of individuals. Given that, different from other online applications, social media use can only be engaged in online, its problematic use may more easily translate into PIU compared to online activities that have offline equivalents.

As hypothesized, Machiavellianism was directly and indirectly associated with PIU via online gaming and online gambling. Given that Machiavellians can have difficulties in real-life social interactions because of their low agreeableness, high emotional manipulativeness, high alexithymia, and low emotional intelligence (Austin, Farrelly, Black, \& Moore, 2007; Jonason \& Krause, 2013), they may feel more comfortable online and prefer online interactions to faceto-face communication. In addition, Machiavellian students have been found to have higher depression when compared to non-Machiavellian students (Bakir et al., 2003). This suggests that there would be higher PIU for individuals high in Machiavellianism, because depression is a consistent predictor of problematic online use (Kircaburun, Kokkinos, et al., 2018).

Machiavellianism was associated with online gaming and online gambling, and in turn, online gaming and online gambling led to higher PIU. Previous studies have associated Machiavellianism with grief play (i.e., trolling in online games), which may present an explanation for this relationship (Ladanyi \& Doyle-Portillo, 2017). Given that individuals high in Machiavellianism have been shown to have competitive feelings and do not comply with moral and ethical behavior in achieving their goals (Clempner, 2017), they may have engaged in grief play to overcome other players and these attempts and efforts may turn into longer times spent gaming online. Similar to gaming, gambling is another competitive environment with additional rewards such as earning real money. Machiavellian behavioral characteristics have been found to associate with reward sensitivity indicating that rewards are important motivators for individuals with high Machiavellian traits (Birkás, Csathó, Gács, \& Bereczkei, 2015). Online gaming and online gambling are two of the most popular specific activities for using the internet and can easily transform into problematic online engagement for some users (Brand et al., 2016).

Parallel to the anticipated outcomes, spitefulness was directly associated with PIU and indirectly using online gambling and online shopping. Similar to Machiavellianism, spitefulness has been associated with higher emotion dysregulation (Zeigler-Hill \& Vonk, 2015), detachment, and disinhibition (Zeigler-Hill \& Noser, 2018) - associations that may result in fulfilling social needs with online gratifications (Gervasi et al., 2017; Niemz, Griffiths, \& Banyard, 2005). Spiteful behaviors are motivated by envious and entitlement emotions (Marcus et al., 2014) and individuals high in spitefulness have higher levels of vulnerable narcissism and lower self-esteem (Marcus et al., 2014), which have been associated with higher pathological online use (Andreassen et al., 2017; Casale, Fioravanti, \& Rugai, 2016). Similarly, spiteful individuals may use online shopping motivated by their envy for others or their constant need for ego-reinforcement because of their vulnerable narcissistic feelings and low self-esteem. In turn, online shopping may lead to compulsive online use when investigating all the different websites for purchasing different products.

This study is among the few that have been conducted to consider the role of dark personality traits on PIU. There are some overlaps between the findings reported here and those among these studies although there are also some contradictory findings. For instance, while this study reported a direct relationship between Machiavellianism and PIU, Machiavellianism was a direct predictor of problematic social media use among university students in a previous study (Kircaburun, Demetrovics, et al., 2018), and it was irrelevant in another study examining problematic online gaming (Kircaburun et al., 2018b). Similarly, narcissism was weakly indirectly associated with PIU via social media use in this study, although it was an important predictor of problematic social media use and problematic gaming. Given that the aforementioned studies have been carried out with completely different university students and gamers, sample differences might be a possible explanation for the different personality traits predicting problematic use of different online activities (e.g., social media, gaming, and internet use). However, these differences also support the notion that (despite their overlap to some extent) specific types of problematic online use (e.g., gaming and social media) and PIU are conceptually different behaviors and separate nosological entities that may have different personality predictors (Brand et al., 2016; Király et al., 2014; Montag et al., 2015). Nonetheless, these preliminary studies indicate that more focus should be given to the dark personality traits when considering PIU and other problematic online behaviors, and more research is warranted on the subject for a better understanding of these relationships.

This study has some limitations that should be addressed in future studies. First, the research data were collected via 
self-report questionnaires in a self-selected sample that are prone to well-known biases and limitations. Future studies should use more in-depth tools such as qualitative or mixed methods among bigger and more representative samples. Second, the cross-sectional design prevents the drawing of causal relationships. In order to be able to indicate causality and directions of these relationships, future studies should employ longitudinal designs. Third, the study sample comprised Turkish undergraduates from a single university; therefore, generalizability of the results is limited. Future studies should attempt to replicate the findings here using different age groups and individuals from different countries and cultures.

Despite the limitations, this is the first study to examine the relationships between dark personality traits, specific online activities, and PIU. Furthermore, this study demonstrated that spitefulness may be directly and indirectly associated with elevated PIU through the use of different online activities. The findings of this study indicate that there should be more research focusing on the role of dark personality traits on problematic online use via significant direct associations of Machiavellianism and spitefulness with PIU. In addition, the results demonstrate that Machiavellianism, spitefulness, sadism, and narcissism were related to different types of internet activities such as online sex, social media use, online gambling, online gaming, and online shopping, all of which have the potential to cause harm in some individuals' lives due to problematic and/or excessive use. Health professionals and clinicians need to take these personality traits into account when considering possible prevention and intervention strategies for PIU. In addition to aforementioned implications, this study tested the theoretical assumptions of I-PACE model and provided empirical evidence for the important role of personality differences in the differentiation of online activities and problematic online use, as well as the important role of preferences of different online activities in determining the levels of PIU.

Funding sources: No financial support was received for this study.

Authors' contribution: Both authors significantly contributed in the preparation of the manuscript.

Conflict of interest: The authors declare no conflict of interest.

\section{REFERENCES}

Abell, L., \& Brewer, G. (2014). Machiavellianism, self-monitoring, self-promotion and relational aggression on Facebook. Computers in Human Behavior, 36, 258-262. doi:10.1016/j. chb.2014.03.076

Alexandraki, K., Stavropoulos, V., Burleigh, T. L., King, D. L., \& Griffiths, M. D. (2018). Internet pornography viewing preference as a risk factor for adolescent Internet addiction: The moderating role of classroom personality factors. Journal of
Behavioral Addictions, 7(2), 423-432. doi:10.1556/2006.7. 2018.34

American Psychiatric Association. (2013). Diagnostic and statistical manual of mental disorders (5th ed.). Arlington, TX: American Psychiatric Association.

Anderson, E. L., Steen, E., \& Stavropoulos, V. (2017). Internet use and problematic Internet use: A systematic review of longitudinal research trends in adolescence and emergent adulthood. International Journal of Adolescence and Youth, 22(4), 430-454. doi:10.1080/02673843.2016.1227716

Andreassen, C. S., Pallesen, S., \& Griffiths, M. D. (2017). The relationship between addictive use of social media, narcissism, and self-esteem: Findings from a large national survey. Addictive Behaviors, 64, 287-293. doi:10.1016/j.addbeh.2016. 03.006

Andreassen, C. S., Torsheim, T., Brunborg, G. S., \& Pallesen, S. (2012). Development of a Facebook Addiction Scale. Psychological Reports, 110(2), 501-517. doi:10.2466/02.09.18. PR0.110.2.501-517

Arpaci, I. (2018). The moderating effect of gender in the relationship between narcissism and selfie-posting behavior. Personality and Individual Differences, 134, 71-74. doi:10.1016/j. paid.2018.06.006

Austin, E. J., Farrelly, D., Black, C., \& Moore, H. (2007). Emotional intelligence, Machiavellianism and emotional manipulation: Does EI have a dark side? Personality and Individual Differences, 43(1), 179-189. doi:10.1016/j.paid.2006. 11.019

Bakir, B., Özer, M., Uçar, M., Güleç, M., Demir, C., \& Hasde, M. (2003). Relation between Machiavellianism and job satisfaction in a sample of Turkish physicians. Psychological Reports, 92(3), 1169-1175. doi:10.2466/PR0.92.3.1169-1175

Baughman, H. M., Jonason, P. K., Veselka, L., \& Vernon, P. A. (2014). Four shades of sexual fantasies linked to the Dark Triad. Personality and Individual Differences, 67, 47-51. doi:10.1016/j.paid.2014.01.034

Birkás, B., Csathó, Á., Gács, B., \& Bereczkei, T. (2015). Nothing ventured nothing gained: Strong associations between reward sensitivity and two measures of Machiavellianism. Personality and Individual Differences, 74, 112-115. doi:10.1016/j. paid.2014.09.046

Brand, M., Young, K. S., Laier, C., Wölfling, K., \& Potenza, M. N. (2016). Integrating psychological and neurobiological considerations regarding the development and maintenance of specific Internet-use disorders: An Interaction of Person-Affect-Cognition-Execution (I-PACE) model. Neuroscience and Biobehavioral Reviews, 71, 252-266. doi:10.1016/ j.neubiorev.2016.08.033

Buckels, E. E., Trapnell, P. D., \& Paulhus, D. L. (2014). Trolls just want to have fun. Personality and Individual Differences, 67, 97-102. doi:10.1016/j.paid.2014.01.016

Casale, S., \& Fioravanti, G. (2018). Why narcissists are at risk for developing Facebook addiction: The need to be admired and the need to belong. Addictive Behaviors, 76, 312-318. doi:10.1016/j.addbeh.2017.08.038

Casale, S., Fioravanti, G., \& Rugai, L. (2016). Grandiose and vulnerable narcissists: Who is at higher risk for social networking addiction? Cyberpsychology, Behavior, and Social Networking, 19(8), 510-515. doi:10.1089/cyber.2016.0189

Christie, R., \& Geis, F. L. (1970). Studies in Machiavellianism. New York, NY: Academic Press. 
Clempner, J. B. (2017). A game theory model for manipulation based on Machiavellianism: Moral and ethical behavior. Journal of Artificial Societies \& Social Simulation, 20(2), 1-12. doi:10.18564/jasss.3301

Corry, N., Merritt, R. D., Mrug, S., \& Pamp, B. (2008). The factor structure of the Narcissistic Personality Inventory. Journal of Personality Assessment, 90(6), 593-600. doi:10.1080/ 00223890802388590

Craker, N., \& March, E. (2016). The dark side of Facebook ${ }^{\circledR}$ : The Dark Tetrad, negative social potency, and trolling behaviours. Personality and Individual Differences, 102, 79-84. doi:10.1016/ j.paid.2016.06.043

Critselis, E., Janikian, M., Paleomilitou, N., Oikonomou, D., Kassinopoulos, M., Kormas, G., \& Tsitsika, A. (2013). Internet gambling is a predictive factor of Internet addictive behavior among Cypriot adolescents. Journal of Behavioral Addictions, 2(4), 224-230. doi:10.1556/JBA.2.2013.4.5

Dalbudak, E., Evren, C., Aldemir, S., \& Evren, B. (2014). The severity of Internet addiction risk and its relationship with the severity of borderline personality features, childhood traumas, dissociative experiences, depression and anxiety symptoms among Turkish university students. Psychiatry Research, 219(3), 577-582. doi:10.1016/j.psychres.2014.02.032

Douglas, H., Bore, M., \& Munro, D. (2012). Distinguishing the Dark Triad: Evidence from the five-factor model and the Hogan development survey. Psychology, 3(03), 237-242. doi:10.4236/psych.2012.33033

Egan, V., Chan, S., \& Shorter, G. W. (2014). The Dark Triad, happiness and subjective well-being. Personality and Individual Differences, 67, 17-22. doi:10.1016/j.paid.2014.01.004

Fox, J., \& Rooney, M. C. (2015). The Dark Triad and trait selfobjectification as predictors of men's use and self-presentation behaviors on social networking sites. Personality and Individual Differences, 76, 161-165. doi:10.1016/j.paid.2014.12.017

Garcia, D., \& Sikström, S. (2014). The dark side of Facebook: Semantic representations of status updates predict the Dark Triad of personality. Personality and Individual Differences, 67, 92-96. doi:10.1016/j.paid.2013.10.001

Gaskin, J. (2016). Gaskination's statistics. Retrieved June 19, 2018, from http://statwiki.kolobkreations.com

George, D., \& Mallery, M. (2010). SPSS for windows step by step: A simple guide and reference, 17.0 update. Boston, MA: Pearson.

Gervasi, A. M., La Marca, L., Lombardo, E., Mannino, G., Iacolino, C., \& Schimmenti, A. (2017). Maladaptive personality traits and Internet addiction symptoms among young adults: A study based on the alternative DSM-5 model for personality disorders. Clinical Neuropsychiatry, 14(1), 20-28.

Greitemeyer, T., \& Sagioglou, C. (2017). The longitudinal relationship between everyday sadism and the amount of violent video game play. Personality and Individual Differences, 104, 238-242. doi:10.1016/j.paid.2016.08.021

Griffiths, M. D. (2000). Internet addiction - Time to be taken seriously? Addiction Research, 8(5), 413-418. doi:10.3109/ 16066350009005587

Griffiths, M. D. (2005). A 'components' model of addiction within a biopsychosocial framework. Journal of Substance Use, 10(4), 191-197. doi:10.1080/14659890500114359

James, S., Kavanagh, P. S., Jonason, P. K., Chonody, J. M., \& Scrutton, H. E. (2014). The Dark Triad, schadenfreude, and sensational interests: Dark personalities, dark emotions, and dark behaviors. Personality and Individual Differences, 68 , 211-216. doi:10.1016/j.paid.2014.04.020

Jonason, P. K., \& Krause, L. (2013). The emotional deficits associated with the Dark Triad traits: Cognitive empathy, affective empathy, and alexithymia. Personality and Individual Differences, 55(5), 532-537. doi:10.1016/j.paid.2013.04.027

Jonason, P. K., Lyons, M., Bethell, E., \& Ross, R. (2013). Different routes to limited empathy in the sexes: Examining the links between the Dark Triad and empathy. Personality and Individual Differences, 54(5), 572-576. doi:10.1016/j.paid. 2012.11.009

Jonason, P. K., \& Webster, G. D. (2010). The dirty dozen: A concise measure of the Dark Triad. Psychological Assessment, 22(2), 420-432. doi:10.1037/a0019265

Jonason, P. K., Zeigler-Hill, V., \& Okan, C. (2017). Good v. evil: Predicting sinning with dark personality traits and moral foundations. Personality and Individual Differences, 104, 180-185. doi:10.1016/j.paid.2016.08.002

Jones, D. N., \& Figueredo, A. J. (2013). The core of darkness: Uncovering the heart of the Dark Triad. European Journal of Personality, 27(6), 521-531. doi:10.1002/per.1893

Kardefelt-Winther, D. (2014). A conceptual and methodological critique of Internet addiction research: Towards a model of compensatory Internet use. Computers in Human Behavior, 31, 351-354. doi:10.1016/j.chb.2013.10.059

Kayiş, A. R., Satici, S. A., Yilmaz, M. F., Şimşek, D., Ceyhan, E., \& Bakioğlu, F. (2016). Big Five-personality trait and Internet addiction: A meta-analytic review. Computers in Human Behavior, 63, 35-40. doi:10.1016/j.chb.2016.05.012

Kim, E. J., Namkoong, K., Ku, T., \& Kim, S. J. (2008). The relationship between online game addiction and aggression, self-control and narcissistic personality traits. European Psychiatry, 23(3), 212-218. doi:10.1016/j.eurpsy.2007.10.010

Király, O., Griffiths, M. D., Urbán, R., Farkas, J., Kökönyei, G., Elekes, Z., Tamás, D., \& Demetrovics, Z. (2014). Problematic Internet use and problematic online gaming are not the same: Findings from a large nationally representative adolescent sample. Cyberpsychology, Behavior, and Social Networking, 17(12), 749-754. doi:10.1089/cyber.2014.0475

Kircaburun, K., Alhabash, S., Tosuntaş, Ş. B., \& Griffiths, M. D. (2018). Uses and gratifications of problematic social media use among university students: A simultaneous examination of the Big Five of personality traits, social media platforms, and social media use motives. International Journal of Mental Health and Addiction. Advance online publication. doi:10.1007/s11469-018-9940-6

Kircaburun, K., Demetrovics, Z., \& Tosuntaş, Ş. B. (2018). Analyzing the links between problematic social media use, Dark Triad traits, and self-esteem. International Journal of Mental Health and Addiction. Advance online publication. doi:10.1007/s11469-018-9900-1

Kircaburun, K., Jonason, P. K., \& Griffiths, M. D. (2018a). The Dark Tetrad traits and problematic social media use: The mediating role of cyberbullying and cybertrolling. Personality and Individual Differences, 135, 264-269. doi:10.1016/j. paid.2018.07.034

Kircaburun, K., Jonason, P. K., \& Griffiths, M. D. (2018b). The Dark Tetrad traits and problematic online gaming: The mediating role of online gaming motives and moderating role of game types. Personality and Individual Differences, 135, 298-303. doi:10.1016/j.paid.2018.07.038 
Kırcaburun, K., Kokkinos, C. M., Demetrovics, Z., Király, O., Griffiths, M. D., \& Çolak, T. S. (2018). Problematic online behaviors among adolescents and emerging adults: Associations between cyberbullying perpetration, problematic social media use, and psychosocial factors. International Journal of Mental Health and Addiction. Advance online publication. doi:10.1007/s11469-018-9894-8

Kline, R. B. (2011). Principles and practices of structural equation modeling (2nd ed.). New York, NY: Guilford.

Kopuničová, V., \& Baumgartner, F. (2016). Personality, depression and problematic Internet use. Psychology and its Contexts, 7(1), 81-92.

Kuss, D. J., Griffiths, M. D., Karila, L., \& Billieux, J. (2014). Internet addiction: A systematic review of epidemiological research for the last decade. Current Pharmaceutical Design, 20(25), 4026-4052. doi:10.2174/13816128113199990617

Ladanyi, J., \& Doyle-Portillo, S. (2017). The development and validation of the Grief Play Scale (GPS) in MMORPGs. Personality and Individual Differences, 114, 125-133. doi:10.1016/j.paid.2017.03.062

Lin, S. S., \& Tsai, C. C. (2002). Sensation seeking and Internet dependence of Taiwanese high school adolescents. Computers in Human Behavior, 18(4), 411-426. doi:10.1016/S07475632(01)00056-5

Lu, W. H., Lee, K. H., Ko, C. H., Hsiao, R. C., Hu, H. F., \& Yen, C. F. (2017). Relationship between borderline personality symptoms and Internet addiction: The mediating effects of mental health problems. Journal of Behavioral Addictions, 6(3), 434-441. doi:10.1556/2006.6.2017.053

Mann, K., Kiefer, F., Schellekens, A., \& Dom, G. (2017). Behavioural addictions: Classification and consequences. European Psychiatry, 44, 187-188. doi:10.1016/j.eurpsy.2017.04.008

Marcus, D. K., Preszler, J., \& Zeigler-Hill, V. (2018). A network of dark personality traits: What lies at the heart of darkness? Journal of Research in Personality, 73, 56-62. doi:10.1016/j. jrp.2017.11.003

Marcus, D. K., Zeigler-Hill, V., Mercer, S. H., \& Norris, A. L. (2014). The psychology of spite and the measurement of spitefulness. Psychological Assessment, 26(2), 563-574. doi:10.1037/a0036039

Montag, C., Bey, K., Sha, P., Li, M., Chen, Y. F., Liu, W. Y., Zhu, Y. K., Li, C. B., Markett, S., Keiper, J., \& Reuter, M. (2015). Is it meaningful to distinguish between generalized and specific Internet addiction? Evidence from a cross-cultural study from Germany, Sweden, Taiwan and China. Asia-Pacific Psychiatry, 7(1), 20-26. doi:10.1111/appy.12122

Niemz, K., Griffiths, M., \& Banyard, P. (2005). Prevalence of pathological Internet use among university students and correlations with self-esteem, the General Health Questionnaire (GHQ), and disinhibition. CyberPsychology \& Behavior, 8(6), 562-570. doi:10.1089/cpb.2005.8.562

O’Meara, A., Davies, J., \& Hammond, S. (2011). The psychometric properties and utility of the Short Sadistic Impulse Scale (SSIS). Psychological Assessment, 23, 523-531. doi:10.1037/a0022400

Ostovar, S., Allahyar, N., Aminpoor, H., Moafian, F., Nor, M. B. M., \& Griffiths, M. D. (2016). Internet addiction and its psychosocial risks (depression, anxiety, stress and loneliness) among Iranian adolescents and young adults: A structural equation model in a cross-sectional study. International Journal of Mental Health and Addiction, 14(3), 257-267. doi:10.1007/s11469-015-9628-0
Özsoy, E., Rauthmann, J. F., Jonason, P. K., \& Ardıç, K. (2017). Reliability and validity of the Turkish versions of Dark Triad Dirty Dozen (DTDD-T), Short Dark Triad (SD3-T), and Single Item Narcissism Scale (SINS-T). Personality and Individual Differences, 117, 11-14. doi:10.1016/j.paid.2017.05.019

Panek, E. T., Nardis, Y., \& Konrath, S. (2013). Mirror or megaphone?: How relationships between narcissism and social networking site use differ on Facebook and Twitter. Computers in Human Behavior, 29(5), 2004-2012. doi:10.1016/j. chb.2013.04.012

Pantic, I., Milanovic, A., Loboda, B., Błachnio, A., Przepiorka, A., Nesic, D., Mazic, S., Dugalic, S., \& Ristic, S. (2017). Association between physiological oscillations in self-esteem, narcissism and Internet addiction: A cross-sectional study. Psychiatry Research, 258, 239-243. doi:10.1016/j. psychres.2017.08.044

Paulhus, D. L., \& Williams, K. M. (2002). The Dark Triad of personality: Narcissism, Machiavellianism, and psychopathy. Journal of Research in Personality, 36(6), 556-563. doi:10.1016/S0092-6566(02)00505-6

Rauthmann, J. F. (2011). Acquisitive or protective self-presentation of dark personalities? Associations among the Dark Triad and self-monitoring. Personality and Individual Differences, 51(4), 502-508. doi:10.1016/j.paid.2011.05.008

Richardson, E. N., \& Boag, S. (2016). Offensive defenses: The mind beneath the mask of the Dark Triad traits. Personality and Individual Differences, 92, 148-152. doi:10.1016/j.paid.2015. 12.039

Shim, J. W., Lee, S., \& Paul, B. (2007). Who responds to unsolicited sexually explicit materials on the Internet? The role of individual differences. CyberPsychology \& Behavior, 10(1), 71-79. doi:10.1089/cpb.2006.9990

Smoker, M., \& March, E. (2017). Predicting perpetration of intimate partner cyberstalking: Gender and the Dark Tetrad. Computers in Human Behavior, 72, 390-396. doi:10.1016/j. chb.2017.03.012

Spada, M. M. (2014). An overview of problematic Internet use. Addictive Behaviors, 39(1), 3-6. doi:10.1016/j.addbeh.2013. 09.007

Stavropoulos, V., Kuss, D. J., Griffiths, M. D., Wilson, P., \& Motti-Stefanidi, F. (2017). MMORPG gaming and hostility predict Internet addiction symptoms in adolescents: An empirical multilevel longitudinal study. Addictive Behaviors, 64, 294-300. doi:10.1016/j.addbeh.2015.09.001

Tabachnick, B. G., \& Fidell, L. S. (2001). Using multivariate statistics (4th ed.). Needham, MA: Allyn \& Bacon.

Tosuntaş, Ş. B., Karadağ, E., Kircaburun, K., \& Griffiths, M. D. (2018). A new phenomenon among emerging adults: Sofalizing and its relationship with social media addiction and psychosocial risk factors. Manuscript submitted for publication.

Tran, U. S., Bertl, B., Kossmeier, M., Pietschnig, J., Stieger, S., \& Voracek, M. (2018). "I'll teach you differences": Taxometric analysis of the Dark Triad, trait sadism, and the Dark Core of personality. Personality and Individual Differences, 126, 19-24. doi:10.1016/j.paid.2018.01.015

Trumello, C., Babore, A., Candelori, C., Morelli, M., \& Bianchi, D. (2018). Relationship with parents, emotion regulation, and callous-unemotional traits in adolescents' Internet addiction. BioMed Research International, 2018, 1-10. doi:10.1155/ 2018/7914261 
van Geel, M., Goemans, A., Toprak, F., \& Vedder, P. (2017) Which personality traits are related to traditional bullying and cyberbullying? A study with the Big Five, Dark Triad and sadism. Personality and Individual Differences, 106, 231-235. doi:10.1016/j.paid.2016.10.063

Vitacco, M. J., \& Rogers, R. (2001). Predictors of adolescent psychopathy: The role of impulsivity, hyperactivity, and sensation seeking. Journal of the American Academy of Psychiatry and the Law, 29(4), 374-382.

Vrabel, J. K., Zeigler-Hill, V., \& Shango, R. G. (2017). Spitefulness and humor styles. Personality and Individual Differences, 105, 238-243. doi:10.1016/j.paid.2016.10.001

West, S. G., Finch, J. F., \& Curran, P. J. (1995). Structural equation models with nonnormal variables: Problems and remedies. In R. H. Hoyle (ed.), Structural equation modeling: Concepts, issues, and applications (pp. 56-75). Thousand Oaks, CA: Sage Publications.

World Health Organization. (2017). ICD-11 Beta draft. Mental, behavioural or neurodevelopmental disorders. Retrieved September 6, 2018, from https://icd.who.int/dev11/1-m/en

Zeigler-Hill, V., \& Noser, A. E. (2018). Characterizing spitefulness in terms of the DSM-5 model of pathological personality traits. Current Psychology, 37(1), 14-20. doi:10.1007/s12144-0169484-5

Zeigler-Hill, V., Noser, A. E., Roof, C., Vonk, J., \& Marcus, D. K. (2015). Spitefulness and moral values. Personality and Individual Differences, 77, 86-90. doi:10.1016/j.paid.2014.12.050

Zeigler-Hill, V., \& Vonk, J. (2015). Dark personality features and emotion dysregulation. Journal of Social and Clinical Psychology, 34(8), 692-704. doi:10.1521/jscp.2015.34.8.692 